\title{
The Comprehensive Factors Affecting the Sleep Quality in Family Caregivers of Patients with Dementia in the Community of South Korea
}

\author{
Park, Heeok ${ }^{1} \cdot$ Kim, Eun Kuyng ${ }^{2} \cdot$ Jeoung, Seo Yeon ${ }^{2} \cdot$ Moon, Kyoung Ja $^{3} \cdot$ Lee, Eun Sook ${ }^{4}$ \\ ${ }^{1}$ Associate Professor, College of Nursing · Research Institute of Nursing Science, Keimyung University, Daegu \\ ${ }^{2}$ Researcher, College of Nursing · Research Institute of Nursing Science, Keimyung University, Daegu \\ ${ }^{3}$ Assistant Professor, College of Nursing · Research Institute of Nursing Science, Keimyung University, Daegu \\ ${ }^{4}$ Assistant Professor, Department of Nursing, Dong-Eui University, Busan, Korea
}

\begin{abstract}
Purpose: The purpose of this study was to provide the comprehensive factors affecting the sleep quality in family caregivers of patients with dementia in South Korea, including patient and caregiver-related factors. Methods: The participant were a total of 156 family caregivers who live with patients with dementia in South Korea. Patient and caregiver-related factors were measured using tools with high reliability. Data collection was performed from May to August 2019, and data were analyzed using descriptive analysis, t-test, ANOVA, Pearson's correlation coefficients, and multiple regression with the SPSS/21.0 program. Results: The significant factors affecting family caregivers' sleep quality were their depression $(\beta=.52, p<.001)$ and their education $(\beta=.23, p=.019)$. Conclusion: There is a need to monitor caregivers' depression and sleep quality. Future studies, biomarker to monitor caregivers' sleep quality to achieve objective evidence. There is a need to provide additional education programs to improve the understanding around caregivers' sleep quality especially for caregivers with low level of education.
\end{abstract}

Key Words: Caregivers; Dementia; Sleep

\section{INTRODUCTION}

The number of persons with dementia (PWD) was estimated as 50 million worldwide in 2019 [1]. Most of PWD are still living at home and family caregivers (FCGs) are responsible for much of the care. FCGs may experience depression and declining quality of life due to dementia care and prolonged family support may lead to family discord and patients' hospitalization [2]. The average caring time required of FCGs at home for PWD is more than 7 hours per day and involves providing primary direct care and activities of daily living.

Home care from FCGs often occurs during the daytime as well as at night due to patients' nighttime activity and decreased cognitive function [3], which leads to even more time commitment from FCGs. Nighttime caring needs of PWD interfere with the FCGs' sleep schedule causing shallow sleep duration, unbalanced sleep patterns, and overall poor sleep. The health outcomes of FCGs' sleep problems include poor mental health, decreased caregiving quality and decreased quality of life [4]. FCGs of PWD have difficulties to maintain their sleep quality, so that it is important to identify the affecting factors to their sleep quality.

Many studies have tried to identify the affecting factors to FCG's sleep quality. Peng and Chang [4] performed the review of the literature related to the factors of FCG's sleep. In the review, factors including care recipients' cognition, behavior, and caregivers' depression were identified in some studies; however, they were not consistently identified in other studies. The factors were more related to FCGs' characteristics than PWDs. The review findings indicated the lack of explicit theoretical frameworks and caregivers' existing health problems.

Corresponding author: Park, Heeok https://orcid.org/0000-0002-8194-0373

College of Nursing, Keimyung University, 1095 Dalgubeol-daero, Dalseo-gu, Daegu 42601, Korea.

Tel: +82-53-258-7655, Fax: +82-53-258-7616, E-mail: hopark@kmu.ac.kr

Received: Jan 27, 2021 / Revised: Feb 9, 2021 / Accepted: Feb 16, 2021

This is an open access article distributed under the terms of the Creative Commons Attribution Non-Commercial License (http://creativecommons.org/licenses/ by-nc/3.0), which permits unrestricted non-commercial use, distribution, and reproduction in any medium, provided the original work is properly cited. 
After the review study, a few studies additionally reported the FCGs' factors to affect sleep quality. FCGs' anxiety, stress, and coping were reported as the affecting factors to sleep quality. In addition, Peng and colleagues [5] included FCGs' health status as a factor to sleep based on the finding of previous review study, but the factor was not found to be statistically significant in the study. Although FCGs of PWD often show low level of sleep quality, few studies were conducted on sleep quality of FCGs of PWD in South Korea. Lee and colleagues [6] identified the patients' factors related to FCGs' sleep quality and the significant factors included patient's depression, agitation, and appetite/eating disorder. However, the study [6] included had limitations because it did not include caregivers' health-related characteristics. Based on the review of previous studies related to the factors of sleep quality in FCGs of PWD, few studies included both PWD- and FCG-related factors and used theoretical frameworks.

Thus, the current study aimed to identify the comprehensive factors of sleep quality in FCGs of PWD. The factors may include PWDs' general, cognitive-physical, and psychosocial characteristics and FCGs' general, health, caring, and psychosocial characteristics. The findings of this study provide the meaningful data to develop interventions to improve FCGs' sleep quality in community.

\section{METHODS}

\section{Study Design}

This study was a descriptive study to identify the factors that affect sleep quality of FCGs of community-dwelling PWDs in South Korea.

\section{Participants}

The participants of this study were FCGs of PWD that use public health centers in three cities of South Korea. The FCGs meeting the following criteria were included: living with and caring for PWD at home; having been providing at least six months of caring for PWD; and a primary caregiver spending the most time of caring for PWD among the family members. The PWD meeting the following criteria were included: diagnosed with dementia by medical doctor; being communicable, living in patient's home alone or with FCGs; having a FCG for a primary caregiver; and visiting public health centers when wanted.

There were 130 participants required per the $G^{*}$ Power
3.2 software program (Heinrich Hein University, Dusseldorf, Germany) with 23 relevant variables, an effect size of 0.20 , and a power of 0.80 . In total, 165 participants were recruited, considering the likely dropout rate and nine participants were dropped by the insufficient responses. Finally, a total of 156 participants were included for the data analysis.

\section{Measurements}

To identify the factors that affect FCGs' sleep quality, PWDs' factors (general, cognitive-physical, and psychosocial characteristics) and FCGs' factors (general, healthrelated, caring, psychosocial characteristics) were included in this study. The measurement of each factor was presented as follows.

\section{1) PWD characteristics}

(1) General characteristics

The PWD's general characteristics included age, gender, and education.

(2) Cognitive and physical characteristics

(1) Activity of daily living (ADL) and instrumental activity of daily living (IADL)

ADL was measured by K-ADL (Korean Activities of Daily Living), of which, a tool developed by Katz [7] was translated by Won et al. [8] to suit Korean participants. The scale consists of seven questions (dressing, washing face and hand, bathing, eating, transfer, toileting, continence) with a 3-point Likert scale (1 point for completely independent, 2 points for partially dependent, and 3 points for completely dependent) and a higher value indicates a higher dependency. The Cronbach's $\alpha$ value of the instrument was .937 in Won et al. study [8] and it was .902 in this study.

IADL was measured by K-IADL (Korean-Instrumental Activities of Daily Living), where a tool developed by Lawton and Brody [9] was translated and adopted by Won et al.[8] to reflect the needs of Koreans. The tool consists of 10 questions, with seven items (decorating, housework, preparing meals, laundry, outgoing for a short distance, handling money, taking medicine) rated on a 3point Likert scale and three items (using transportation, shopping, using telephone) rated on a 4-point Likert scale (1 point for completely independent, 2 or 3 points for partially dependent, and 4 points for completely dependent); a higher value indicates a higher dependency. The reliability of the tool was determined to be .91 at the time of development. The Cronbach's $\alpha$ value of the instrument 
was .935 in Won et al study [8] and it was .946 in this study.

(2) Memory and behavioral problems

In this study, we used the Korean Version of the Revised Memory and Behavior Problems Checklist (KRMBPC), which was adapted by Lee and Yoon [10] from the Revised Memory and Behavior Problems Checklist (R-MBPC) developed by Zarit [11] and revised by Teri et al [12]. K-RMBPC consists of 24 questions with sub-items of depression (9 questions), destructive behavior (8 questions), and representative of memory-related problems (7 questions), to measure memory and behavioral problems of dementia. Lower scores mean fewer problems with memory and behavior. The Cronbach's $\alpha$ value of the instrument was .840 in Teri et al' study [12] and .880 in Lee and Yoon' study [10]. In this study, the tool's Cronbach's $\alpha$ was .908.

(3) Psychosocial characteristics

(1) Depression

In this study, the Korean version of the Cornell Scale for Depression in Dementia (CSDD) was used to measure the depression level of PWD $[13,14]$. CSDD is a tool with 19 questions designed to assess depression symptoms. It consists of five sub-scales: mood-related signs, behavioral disturbance, physical signs, cyclic functions, and ideational disturbance. The score ranges from 0 to 38 , and a higher score indicates more severe depression. Cut-off points of depression are 8 points, where 0 to 7 points indicate normal, 8 to 12 points is mild depression, and more than 13 points is severe depression. The Cronbach's $\alpha$ of this instrument was .78 in Lee et al.' study [14] and it was .872 in this study.

\section{(2) Sleepiness}

Daytime sleepiness was measured using the Epworth Sleepiness Scale (ESS), developed by Johns [15] and Korean version of ESS by Mapi Research Trust [16]. That tool allows an overall assessment of sleepiness with a self-report questionnaire that sets up eight daily situations that can cause sleepiness and evaluates the degree of sleepiness for each situation with 0 to 3 points. The degree of weekly excessive sleepiness is calculated by adding up the sleepiness scores in eight situations, with possible scores ranging from 0 to 24, and a higher ESS score indicates more sleepiness. The Cronbach's $\alpha$ of the instrument was .880 in Johns' study [15] and .840 in this study.

\section{2) FCG characteristics}

(1) General characteristics
General characteristics of FCGs included age, gender, education, marital status and monthly income.

(2) Health-related characteristics

The health-related characteristics included subjective health status, presence of chronic diseases, presence of regular exercise, and presence of meditation or yoga

(3) Caring characteristics

Caring characteristics included family relation and duration of caring.

(4) Psychosocial characteristics

(1) Depression

Depression was measured using the Korean version of the Center for Epidemiologic Studies Depression Scale (CES-D), which was developed by Redloff [17], modified, and standardized by Chon \& Rhee [18]. The CES-D consists of 20 questions, where depressive symptoms experienced over the prior week are assessed on a 4-point Likert scale, except questions $4,8,12$ and 16 with positive meanings, which are scored in reverse. Higher scores indicate higher levels of depression. At the time of development, Cronbach's $\alpha$ for that tool was 85 [17] and.89 in Chon \& Rhee [18]. In this study, the tool's Cronbach's $\alpha$ was .894 .

\section{(2) Burden}

The caregivers' feeling of burden was measured using the supplemented version of the Burden Interview (BI), which was originally developed by Zarit et al.[19] and modified by Kwon [20]. It consists of 28 items on a 5-point Likert scale, with a range of possible scores from 28 to 140; the higher the score, the higher the burden of support felt by the caregiver. The reliability using Cronbach's $\alpha$ was .87 at the time of development [19] and .96 in Kwon [20]. In this study, the tool's Cronbach's $\alpha$ was .963.

\section{3) FCGs' Sleep Quality}

FCGs' sleep quality was measured by the revised Korean version of the Pittsburgh Sleep Quality Index (PSQI$\mathrm{K}$ ), originally developed by Buysse et al. [21] and modified and supplemented by Sohn et al. [22]. PSQI-K consists of 19 questions in seven categories, including sleep quality, sleep latency, sleep duration, habitual sleep efficiency, sleep disturbances, use of sleeping medication, and daytime dysfunction. The score of each question is $0 \sim 3$. The total score ranges from 0 to 21 points by adding up the scores from 7 categories, and a higher total score indicates a lower quality of sleep. A score over 5 points is defined as a poor sleeper, and below 5 points, a good 
sleeper [21]. In Sohn et al. [22], Cronbach's $\alpha$ for that tool was .84 and in this study, it was .771.

\section{Data Collection}

This study was performed after approval from the affiliated Institutional Review Board (IRB) (40525-201811-HR100-03). Data collection was conducted from May 2019 to August 2019 from the FCGs' using 3 public health centers in South Korea. The researcher explained the purpose and contents of the research to each director of public health centers before getting approvals to visit and collect the data. The researcher explained the purpose and process of the research to the FCGs and PWDs and started data collection when they agreed to participate in the study and gave written informed consents. The questionnaires were divided to PWDs and FCGs and the approvals of consent form were obtained by each. If PWDs had cognitive or functional problems, their legal representatives gave the approvals. The FCGs answered both questionnaires on patient- and caregiver-related factors. For CSDD, the researcher explained the questionnaire to FCGs and helped the FCGs to answer the instrument. When they faced difficulties in filling it due to vision problems, researchers read aloud the questions to them and wrote down their responses on their behalf. The survey took about 30 minutes and a small gift was given to each participant when the survey was completed.

\section{Data Analysis}

The data of this study were analyzed using SPSS (IBM Corp. Released 2012. IBM SPSS Statistics for Windows, Version 21.0. Armonk, NY: IBM Corp.). Data analysis was performed as follows: FCGs and PWD factors were analyzed with descriptive statistics such as number and percentage; the differences in FCGs' sleep quality according to PWDs' and FCGs' characteristics were analyzed with t-test, ANOVA, Scheffé's test, and Games-Howell post hoc test; the correlation between FCGs' sleep quality and PWDs' and FCGs' characteristics was analyzed using Pearson's correlation; and factors affecting the FCGs' sleep quality were analyzed using hierarchical regression.

\section{RESULTS}

\section{Characteristics of Patients and Family Caregivers}

The characteristics of PWD and FCGs are shown in Table 1. The patients' characteristics were as follows.
There were 95 females (60.9\%), and the most common age group was $70 \sim 79$ years old $(n=70,44.9 \%)$, with a mean age (mean \pm standard deviation) of $77.8 \pm 8.07$ years old. Altogether, 64 patients (41.0\%) were educated through no formal education. The mean ADL score was 10.26 \pm 3.33 , mean IADL score $19.75 \pm 6.55$, and mean memory and behavior problems score was $58.28 \pm 12.42$. The mean depression score was $9.87 \pm 6.46$ (indicating mild depression) and mean degree of sleepiness was 8.88 \pm 4.21 .

The FCGs' characteristics were as follows. There were 98 females (62.8\%); the most common age group was 40 to 59 years old, with 68 people $(43.6 \%)$, and the average age was $53.46 \pm 16.30$. Sixty-seven caregivers had at least a university graduation (42.9\%), and 124 caregivers (79.5\%) were married. One hundred and thirty-six caregivers (87.2\%) had a monthly income of more than one million KRW (South Korean Won). Eighty-three caregivers (53.2\%) reported their subjective health status as 'average', and, 82 caregivers (52.6\%) had no chronic diseases. One hundred and five caregivers $(67.3 \%)$ did not exercise regularly and 133 caregivers $(85.3 \%)$ did not meditate or do yoga. Seventy-three caregivers $(46.8 \%)$ were the children of the patients.

The duration of caring was remarkably diverse, with a mean of $44.30 \pm 62.52$ months. The mean depression score was $18.63 \pm 8.49$, which was higher than that of the patients, the mean burden score was $79.86 \pm 20.08$, and the mean sleep quality score was $6.42 \pm 3.48$, indicating poor quality of sleep.

\section{Differences in Sleep Quality of Family Caregivers Based on the Characteristics of Patients and Family Caregivers}

Table 2 shows the differences in sleep quality according to the characteristics of patients and FCGs. The sleep quality per the characteristics of patients was significant in terms of gender, with males having a lower sleep quality than females $(\mathrm{t}=2.27, p=.024)$. Looking at the sleep quality according to the characteristics of FCGs, there were significant differences in education $(t=3.73, p=$ .006), monthly income ( $\mathrm{t}=4.96, p=.008)$, subjective health status $(\mathrm{t}=6.60, p=.002)$, and chronic disease $(\mathrm{t}=3.43, p=$ $.001)$. Sleep quality was lower in those with no education compared to university graduates and in those with a monthly income of less than one million KRW compared to those with more than three million KRW. The caregivers who reported their subjective health status as 'bad' had lower sleep quality than those who reported it as 'good,' and those with chronic diseases had lower sleep 
Table1. Characteristics of Patient and Family Caregivers

$(N=156)$

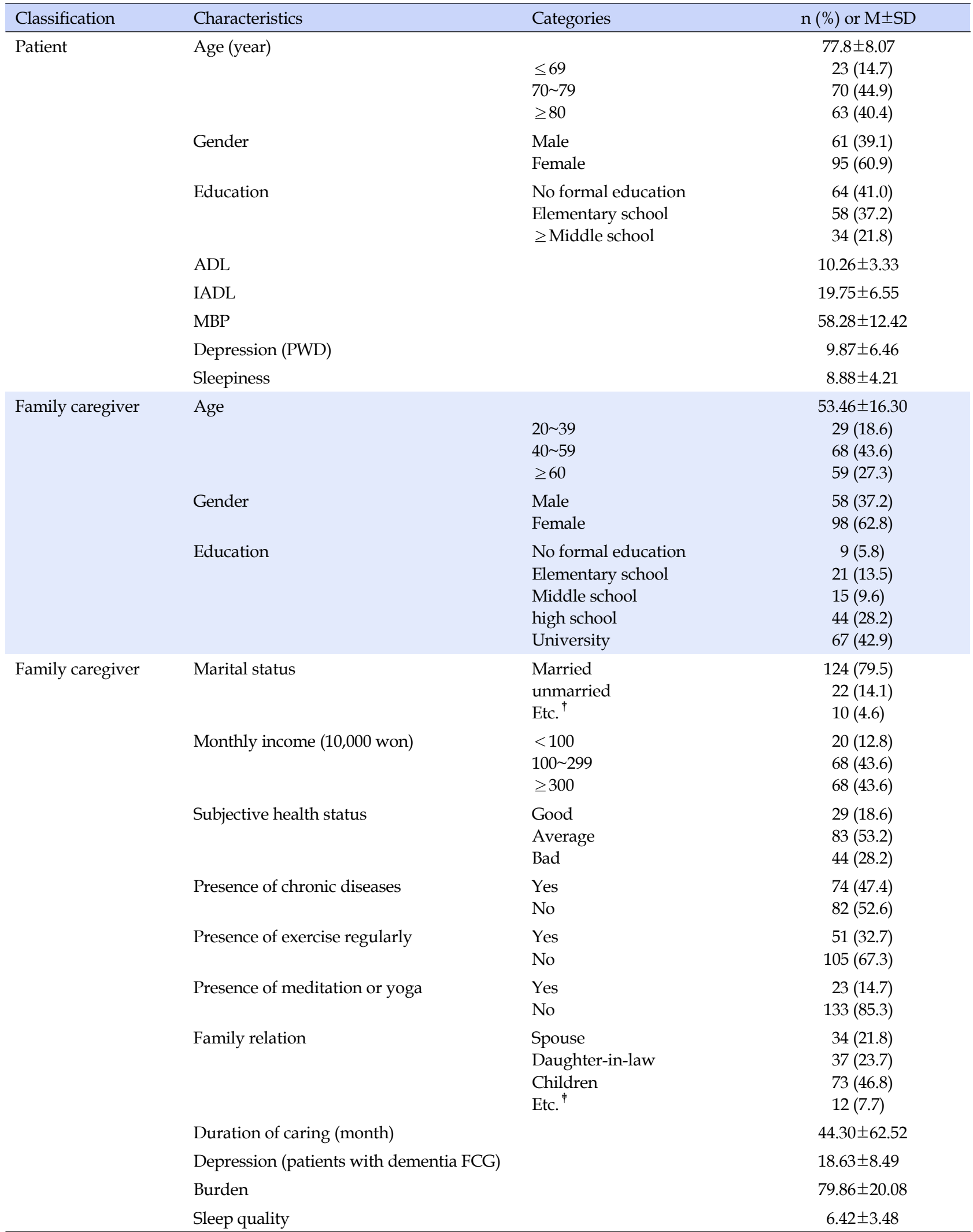

$\mathrm{ADL}=$ Activities of daily living; FCG=Family caregivers; IADL=Instrumental activities of daily living; $\mathrm{M}=\mathrm{Mean}$; $\mathrm{MBP}=\mathrm{Memory}$ and behavior problems; $\mathrm{PWD}=$ Patients with dementia; $\mathrm{SD}=$ Standard deviation; ${ }^{\dagger} \mathrm{Etc}=$ Divorce, bereaved, separation ${ }^{\dagger}$ Etc $12=$ granddaughter 9 , unknown 2 , grandson's wife 1. 
Table 2. Differences in Sleep Quality of Family Caregivers Based on the Characteristics of Patients and Family Caregivers

\begin{tabular}{|c|c|c|c|c|}
\hline Classification & Characteristics & Categories & $\mathrm{M} \pm \mathrm{SD}$ & $\begin{array}{l}\text { t or F }(p) \\
\text { Scheffé or Games-Howell }\end{array}$ \\
\hline \multirow[t]{3}{*}{ Patient } & Age (year) & $\begin{array}{l}\leq 69 \\
70 \sim 79 \\
\geq 80\end{array}$ & $\begin{array}{l}6.69 \pm 4.32 \\
6.07 \pm 2.90 \\
6.73 \pm 3.76\end{array}$ & $0.66(.515)$ \\
\hline & Gender & $\begin{array}{l}\text { Male } \\
\text { Female }\end{array}$ & $\begin{array}{l}7.21 \pm 3.75 \\
5.92 \pm 3.22\end{array}$ & $2.27(.024)$ \\
\hline & Education & $\begin{array}{l}\text { No formal education } \\
\text { Elementary school } \\
\geq \text { Middle school }\end{array}$ & $\begin{array}{l}6.54 \pm 3.45 \\
6.46 \pm 3.91 \\
2.79 \pm 2.79\end{array}$ & $0.14(.862)$ \\
\hline \multirow[t]{10}{*}{ Family caregiver } & Age & $\begin{array}{l}20 \sim 39 \\
40 \sim 59 \\
\geq 60\end{array}$ & $\begin{array}{l}5.75 \pm 2.70 \\
6.00 \pm 3.00 \\
7.25 \pm 4.17\end{array}$ & $2.76(.066)$ \\
\hline & Gender & $\begin{array}{l}\text { Male } \\
\text { Female }\end{array}$ & $\begin{array}{l}6.46 \pm 3.90 \\
6.40 \pm 3.23\end{array}$ & $0.09(.921)$ \\
\hline & Education & $\begin{array}{l}\text { No formal education } \\
\text { Elementary school }^{\mathrm{a}} \\
\text { Middle school }^{\mathrm{c}} \\
\text { High school }^{\mathrm{d}} \\
\text { University }^{\mathrm{e}}\end{array}$ & $\begin{array}{l}10.22 \pm 4.05 \\
6.71 \pm 4.16 \\
5.80 \pm 3.23 \\
6.72 \pm 3.66 \\
5.77 \pm 2.79\end{array}$ & $\begin{array}{c}3.73(.006) \\
\quad \mathrm{a}>\mathrm{e}\end{array}$ \\
\hline & Marital status & $\begin{array}{l}\text { Married } \\
\text { Unmarried } \\
\text { Etc. }^{\dagger}\end{array}$ & $\begin{array}{l}6.45 \pm 3.57 \\
6.04 \pm 3.21 \\
7.00 \pm 3.23\end{array}$ & $0.26(.766)$ \\
\hline & Monthly income (10,000 won) & $\begin{array}{l}<100^{\mathrm{a}} \\
100 \sim 299^{\mathrm{b}} \\
\geq 300^{\mathrm{c}}\end{array}$ & $\begin{array}{l}8.55 \pm 4.12 \\
6.41 \pm 3.62 \\
5.82 \pm 2.90\end{array}$ & $\begin{array}{c}4.96(.008) \\
a>c\end{array}$ \\
\hline & Subjective health status & $\begin{array}{l}\text { Good }^{\mathrm{a}} \\
\text { Average }^{\mathrm{b}} \\
\text { Bad }^{\mathrm{c}}\end{array}$ & $\begin{array}{l}4.86 \pm 2.86 \\
6.27 \pm 3.23 \\
7.75 \pm 3.88\end{array}$ & $\begin{array}{c}6.60(.002) \\
\quad \mathrm{c}>\mathrm{a}\end{array}$ \\
\hline & Presence of chronic diseases & $\begin{array}{l}\text { Yes } \\
\text { No }\end{array}$ & $\begin{array}{l}7.41 \pm 3.81 \\
5.53 \pm 2.91\end{array}$ & $3.43(.001)$ \\
\hline & Presence of regular exercise & $\begin{array}{l}\text { Yes } \\
\text { No }\end{array}$ & $\begin{array}{l}6.11 \pm 3.35 \\
6.58 \pm 3.55\end{array}$ & $-0.77(.438)$ \\
\hline & Presence of meditation or yoga & $\begin{array}{l}\text { Yes } \\
\text { No }\end{array}$ & $\begin{array}{l}6.56 \pm 2.64 \\
6.40 \pm 3.62\end{array}$ & $0.20(.841)$ \\
\hline & Family relation & $\begin{array}{l}\text { Spouse } \\
\text { Daughter-in-law } \\
\text { Child } \\
\text { Etc. }^{\dagger}\end{array}$ & $\begin{array}{l}6.94 \pm 3.96 \\
6.29 \pm 2.92 \\
6.28 \pm 3.50 \\
6.25 \pm 3.84\end{array}$ & $0.30(.819)$ \\
\hline
\end{tabular}

$\mathrm{SD}=$ Standard deviation; M=Mean; ${ }^{\dagger}$ Etc=Divorce, bereaved, separation; ${ }^{\dagger}$ Etc $12=$ granddaughter 9, unknown 2, grandson's wife 1.

quality than those without chronic diseases.

\section{Correlation between the Characteristics of $\mathrm{Pa}-$ tients and FCGs and Sleep Quality of Caregivers}

The relationship between the characteristics of patients and FCGs and sleep quality of caregivers is shown in
Table 3. Patients' ADL $(\mathrm{r}=.16, p=.036)$ and depression $(\mathrm{r}=$ $.22, p=.005$ ) showed significantly positive correlation with FCGs' sleep quality. FCGs' duration of caring $(\mathrm{r}=.18, p=$ $.018)$, depression $(\mathrm{r}=.51, p<.001)$, and burden $(\mathrm{r}=.27, p=$ .001 ) showed a significant positive correlation with FCGs' sleep quality. 
Table 3. Correlation between the Characteristics of Patients and Family Caregivers and Sleep Quality of Caregivers $(N=156)$

\begin{tabular}{|c|c|c|c|c|c|c|c|c|c|}
\hline \multirow{3}{*}{ Variables } & \multicolumn{5}{|c|}{ Patient } & \multicolumn{4}{|c|}{ Family caregiver } \\
\hline & 1 & 2 & 3 & 4 & 5 & 6 & 7 & 8 & 9 \\
\hline & $\mathrm{r}(p)$ & $r(p)$ & $r(p)$ & $r(p)$ & $r(p)$ & $r(p)$ & $\mathrm{r}(p)$ & $\mathrm{r}(p)$ & $\mathrm{r}(p)$ \\
\hline 1. ADL & 1 & & & & & & & & \\
\hline 2. IADL & $\begin{array}{c}.76 \\
(<.001)\end{array}$ & 1 & & & & & & & \\
\hline 3. MBP & $\begin{array}{c}.50 \\
(<.001)\end{array}$ & $\begin{array}{c}.53 \\
(<.001)\end{array}$ & 1 & & & & & & \\
\hline 4. Depression & $\begin{array}{c}.36 \\
(<.001)\end{array}$ & $\begin{array}{c}.43 \\
(<.001)\end{array}$ & $\begin{array}{c}.49 \\
(<.001)\end{array}$ & 1 & & & & & \\
\hline 5. Sleepiness & $\begin{array}{c}.31 \\
(<.001)\end{array}$ & $\begin{array}{c}.28 \\
(<.001)\end{array}$ & $\begin{array}{c}.44 \\
(<.001)\end{array}$ & $\begin{array}{c}.37 \\
(<.001)\end{array}$ & 1 & & & & \\
\hline $\begin{array}{l}\text { 6. Duration of } \\
\text { caring }\end{array}$ & $\begin{array}{l}-.64 \\
(.427)\end{array}$ & $\begin{array}{c}.03 \\
(.676)\end{array}$ & $\begin{array}{l}-.02 \\
(.719)\end{array}$ & $\begin{array}{l}-.00 \\
(.925)\end{array}$ & $\begin{array}{l}-.12 \\
(.125)\end{array}$ & 1 & & & \\
\hline 7. Depression & $\begin{array}{c}.28 \\
(<.001)\end{array}$ & $\begin{array}{c}.16 \\
(.037)\end{array}$ & $\begin{array}{c}.34 \\
(<.001)\end{array}$ & $\begin{array}{c}.29 \\
(<.001)\end{array}$ & $\begin{array}{c}.37 \\
(<.001)\end{array}$ & $\begin{array}{c}.09 \\
(.251)\end{array}$ & 1 & & \\
\hline 8. Burden & $\begin{array}{c}.17 \\
(.029)\end{array}$ & $\begin{array}{c}.26 \\
(.001)\end{array}$ & $\begin{array}{c}.39 \\
(.<.001)\end{array}$ & $\begin{array}{c}.27 \\
(<.001)\end{array}$ & $\begin{array}{c}.39 \\
(<.001)\end{array}$ & $\begin{array}{l}-.03 \\
(.709)\end{array}$ & $\begin{array}{c}.62 \\
(<.001)\end{array}$ & 1 & \\
\hline 9. Quality sleep & $\begin{array}{c}.16 \\
(.036)\end{array}$ & $\begin{array}{c}.12 \\
(.117)\end{array}$ & $\begin{array}{c}.09 \\
(.231)\end{array}$ & $\begin{array}{c}.22 \\
(.005)\end{array}$ & $\begin{array}{c}.12 \\
(.114)\end{array}$ & $\begin{array}{c}.18 \\
(.018)\end{array}$ & $\begin{array}{c}.51 \\
(<.001)\end{array}$ & $\begin{array}{c}.27 \\
(.001)\end{array}$ & 1 \\
\hline
\end{tabular}

$\mathrm{ADL}=$ Activities of daily living; $\mathrm{IADL}=$ Instrumental activities of daily living; $\mathrm{MBP}=$ Memory and behavior problem.

\section{Factors Affecting Sleep Quality of FCGs}

As a result of testing the hypothesis before regression analysis in this study, the Durbin-Watson value was 2.092, which is close to 2 , indicating no autocorrelation of error. The tolerance limit was $0.292 \sim 0.864$ which was below 1.0, and the variation inflation factor (VIF) was 1.130 $\sim 3.429$, which did not exceed the standard value of 10 , indicating no multicollinearity.

As a result of hierarchical regression analysis (Table 4), it was found that the PWD's depression $(\beta=.19, p=.047)$ and FCG's subjective health status (bad) $(\beta=.28, p=.017)$ had a significant effect on FCGs' sleep quality in the first hierarchy where significant general characteristics (PWD: gender; FCG: education, monthly income), significant FCG's health-related characteristics (subjective health status, presence of chronic diseases), PWD's cognitive and physical characteristics (ADL, IADL, memory and behavioral problems), and PWD's psychosocial characteristics (depression, sleepiness) were controlled. The explanatory power was $22 \%$.

In the second hierarchy to which the duration of care (significant FCG's caring characteristics) was added, the explanatory power increased by $3 \%$, and it was found to be significant $(p<.001)$. It was found that the PWD's de- pression $(\beta=.20, p=.034)$, FCG's subjective health status (Average) $(\beta=.21, p=.038)$, FCG's subjective health status (bad) $(\beta=.29, p=.016)$, and duration of care $(\beta=.18, p=.024)$ did significantly affect sleep quality. In the third hierarchy, where FCG's depression and burden were added, $15 \%$ increased significantly $(p<.001)$, and the overall explanatory power was $40 \%$. It was found that FCG's education (no formal education) $(\beta=.23, p=.019)$ and depression $(\beta=.52, p<.001)$ had a significant effect on FCGs' sleep quality. That is, FCGs with no formal education were found to have worse sleep quality than those with university education, and the more severe the depression, the worse the sleep quality.

\section{DISCUSSION}

This study is the first to comprehensively consider patient-related and caregiver-related factors, as well as cognitive-physical, psychosocial, disease-related, and caring characteristics, to identify the influencing factors on sleep quality in caregivers of PWD at home in South Korea. The significant factors on sleep quality in caregivers of patients with dementia were shown as education level and depression.

This study showed that the sleep quality of FCGs of 
Table 4. Affecting Sleep Quality of Family Caregivers

$(N=156)$

\begin{tabular}{|c|c|c|c|c|c|c|c|}
\hline \multirow{2}{*}{ Classification } & \multirow{2}{*}{ Characteristics } & \multicolumn{2}{|c|}{ Model 1} & \multicolumn{2}{|c|}{ Model 2} & \multicolumn{2}{|c|}{ Model 3} \\
\hline & & $\beta$ & $p$ & $\beta$ & $p$ & $\beta$ & $p$ \\
\hline (Constant) & & & .018 & & .029 & & .008 \\
\hline \multicolumn{8}{|l|}{ Patient } \\
\hline Gender & $\begin{array}{l}\text { Male } \\
\text { Female (reference) }\end{array}$ & .10 & .197 & .09 & .211 & .03 & .582 \\
\hline ADL & & .16 & .175 & .20 & .095 & .03 & .761 \\
\hline IADL & & -.10 & .396 & -.15 & .226 & .01 & .910 \\
\hline RMBPC & & -.08 & .418 & -.07 & .431 & -.15 & .095 \\
\hline Depression & & .19 & .047 & .20 & .034 & .13 & .128 \\
\hline Sleepiness & & .05 & .526 & .07 & .411 & -.04 & .565 \\
\hline \multicolumn{8}{|l|}{ Family caregiver } \\
\hline Education & $\begin{array}{l}\text { No formal education } \\
\text { Elementary school } \\
\text { Middle school } \\
\text { High school } \\
\text { University (reference) }\end{array}$ & $\begin{array}{r}.18 \\
-.02 \\
-.09 \\
.06\end{array}$ & $\begin{array}{l}.094 \\
.822 \\
.304 \\
.458\end{array}$ & $\begin{array}{r}.16 \\
-.01 \\
-.12 \\
.07\end{array}$ & $\begin{array}{l}.138 \\
.900 \\
.168 \\
.426\end{array}$ & $\begin{array}{r}.23 \\
.05 \\
-.05 \\
.09\end{array}$ & $\begin{array}{l}.019 \\
.521 \\
.492 \\
.215\end{array}$ \\
\hline Monthly income & $\begin{array}{l}>100 \\
100 \sim 299 \\
\geq 300 \text { (reference) }\end{array}$ & $\begin{array}{l}.00 \\
.01\end{array}$ & $\begin{array}{l}.975 \\
.872\end{array}$ & $\begin{array}{r}.00 \\
-.02\end{array}$ & $\begin{array}{l}.991 \\
.830\end{array}$ & $\begin{array}{l}-.05 \\
-.11\end{array}$ & $\begin{array}{l}.620 \\
.187\end{array}$ \\
\hline $\begin{array}{l}\text { Subjective health } \\
\text { status }\end{array}$ & $\begin{array}{l}\text { Good }^{\mathrm{a}} \text { (reference) } \\
\text { Average }^{\mathrm{b}} \\
\text { Bad }^{\mathrm{c}}\end{array}$ & $\begin{array}{l}.20 \\
.28\end{array}$ & $\begin{array}{l}.060 \\
.017\end{array}$ & $\begin{array}{l}.21 \\
.29\end{array}$ & $\begin{array}{l}.038 \\
.016\end{array}$ & $\begin{array}{l}.09 \\
.11\end{array}$ & $\begin{array}{l}.352 \\
.303\end{array}$ \\
\hline $\begin{array}{l}\text { Presence of chronic } \\
\text { diseases }\end{array}$ & $\begin{array}{l}\text { Yes } \\
\text { No (reference) }\end{array}$ & .12 & .155 & .10 & .236 & .07 & .343 \\
\hline Duration of caring & & & & .18 & .024 & .12 & .099 \\
\hline Depression & & & & & & .52 & $<.001$ \\
\hline \multirow[t]{2}{*}{ Burden } & & & & & & -.06 & .544 \\
\hline & & \multicolumn{2}{|c|}{$\begin{array}{c}\mathrm{R}^{2}=.22, \text { Ad. } \mathrm{R}^{2}=.14 \\
\mathrm{~F}=2.72, p<.001\end{array}$} & \multicolumn{2}{|c|}{$\begin{array}{c}\mathrm{R}^{2}=.25, \text { Adj. } \mathrm{R}^{2}=.16 \\
\mathrm{~F}=2.96, p<.001\end{array}$} & \multicolumn{2}{|c|}{$\begin{array}{c}\mathrm{R}^{2}=.40, \text { Adj. } \mathrm{R}^{2}=.32, \\
\mathrm{~F}=5.11, p<.001\end{array}$} \\
\hline$\triangle \mathrm{R}^{2}$ & & & & \multicolumn{2}{|c|}{.03} & \multicolumn{2}{|c|}{.15} \\
\hline Durbin-Watson & & & & & & \multicolumn{2}{|c|}{2.092} \\
\hline
\end{tabular}

Adj.=Adjusted; $\mathrm{ADL}=$ Activities of daily living; $\mathrm{IADL}=$ Instrumental activities of daily living; $\mathrm{MBP}=$ Memory and behavior problems.

PWD was affected by their depression and level of education. First, depression of FCGs is reported as the most important psychological factor in previous studies related to sleep disorders [4]. Depression is accompanied by sleep disorders, with decreased interest, appetite, and thinking abilities [23], resulting in sleep disorders in 65\% of depressed patients [24] and making its management essential to improve the sleep quality for FCGs. Depression in FCGs of PWD has been reported to be two or three times more frequent than in the general population [25]. Further, the caregivers experience a variety of causes, such as their daily lives being more patient-oriented than their own lives, which interferes with their lifestyles, and elicits complicated emotions of love, anger, and guilt for the patients. Therefore, it is essential to manage not only the sleep quality but also their depression, to improve the sleep quality of the FCGs of PWD.

To improve the depression of FCGs of PWD, various programs, such as those on skills of managing behavioral problems of PWD and cognitive strategy on negative 
emotions, mediation of inner resources, counselling, and support groups, have been used [26,27]. Therefore, not only depression but also the ability to provide information, support to patients, and stress coping, as well as efficacy, have improved [26]. Abrahams et al. [27] also emphasized the importance of occupational therapy for caregivers by presenting interventional programs that include skills training to improve the daily lives of PWD, counseling for depression, and stress management. The existing depression management programs for FCGs of PWD seem to be able to meet the various psychological needs experienced by them while caring for the patient. In particular, it is necessary to identify the depressive characteristics of FCGs of PWD at home and build intervention programs based on the results.

The results of this study show that the educational background of FCGs of PWD was a significant factor affecting their sleep quality. In international studies, the educational background of FCGs did not affect the sleep quality [28], which was not consistent with the results of the current study. Since the level of education is an indicator of economic capacity, information, and service utilization, those with less education might be more prone to poor living environments, psychological stress, risky behavior, lack of sleep education, and poor health that would harm sleep quality [29]. Those with higher education can improve their support environment by appropriately using the information and the help around them. A few previous studies have indicated a relationship between education and sleep quality, so there is a need to investigate this relationship further.

Besides, to improve the sleep quality of the caregivers, it is necessary to provide appropriate educational methods for sleep management, with their educational level and experiences taken into consideration. In particular, there is a need for easy-to-use information technology that provides support services, home services, self-help groups, and sleep improvement methods that are accessible to FCGs, regardless of their level of education. Even though many studies on sleep quality of PWD have been conducted to date, those on sleep quality of FCGs who care for the patients long-term are insufficient. This study is significant in that it identified factors affecting the sleep quality of FCGs. The results of this study are useful to find nursing intervention measures to improve the sleep quality of FCGs, and the study suggests a need to develop a sleep quality improvement program based on the degree of depression and education level of the caregivers.

The findings of this current study showed that the daily life of PWD did not affect the sleep quality of FCGs.
The result of this study was similar with that of Lee et al. [6], in that the sleep quality of caregivers of patients with dementia and mild cognitive impairment at home were not affected by the ADL of PWD The results in this study could be attributed the fact that, in the case of PWD at home, the level of ADL are higher than those of PWD in hospitals specialized for older adults or nursing homes [30]. Thus, it apparently does not affect the burden and sleep quality of the caregivers directly. However, deterioration in daily life is the leading cause of hospitalization and should be managed at home first.

The current study has limitations in that it did not identify exogenous variables such as caffeine intake and environmental factors like home temperature and humidity, which could also affect the sleep quality of FCGs. Further, the results were not generalized by collecting data from multiple cities. Since only self-reported questionnaires were used to assess sleep quality, we suggest using an objective tool such as personal wearable devices that can monitor sleep patterns to increase the validity of new research. In this study, researchers helped FCG to answer the patients' and FCGs' depression so that the answering could affect the findings of the study. For further studies, researchers need to observe and measure the patients and FCG 's depression for each if possible.

\section{CONCLUSION}

The purpose of this study was to identify factors affecting the sleep quality of FCGs of PWD at home and to provide necessary data for the development of a program for the management of sleep quality of the caregivers. The results of this study indicated that FCGs' sleep quality was not significantly affected by patient-related factors, and the depression and the educational background of the caregivers had a significant effect on their sleep quality. In order to improve the sleep quality of FCGs at home, it is necessary to check not only the sleep quality itself but also their depressive state and to identify the cause of depression and mitigate them. Moreover, it is necessary to provide adequate sleep management programs considering the educational background of the caregivers and prioritize managing those with less educational opportunities for sleep management.

\section{CONFLICTS OF INTEREST}

The authors declared no conflict of interest.

\section{AUTHORSHIP}

Study design - PH; Data collection and analysis - KEK and JSY; 
Writing manuscript - PH, KEK, MKJ and LES; Approval for the final submission - PH, KEK, JSY, MKJ and LES.

\section{REFERENCES}

1. Alzheimer's Disease International. World alzheimer's report 2019 [Internet]. London: Alzheimer's Disease International; 2019 [updated 2019; cited 2020 January 10]. Available from: https://www.alzint.org/u/WorldAlzheimerReport2019.pdf

2. Luppa M, Luck T, Brähler E, König HH, Riedel-Heller SG. Prediction of institutionalisation in dementia. Dementia and Geriatric Cognitive Disorders. 2008;6(1):65-78. https://doi.org/10.1159/000144027

3. Etters L, Goodall D, Harrison BE. Caregiver burden among dementia patient caregivers: a review of the literature. Journal of the American Academy of Nurse Practitioners. 2008; 20(8):423-8. https://doi.org/10.1111/j.1745-7599.2008.00342.x

4. Peng HL, Chang YP. Sleep disturbance in family caregivers of individuals with dementia: a review of the literature. Perspectives in Psychiatric Care. 2013;49(2):135-46. https://doi.org/10.1111/ppc.12005

5. Peng HL, Lorenz RA, Chang YP. Factors associated with sleep in family caregivers of individuals with dementia. Perspectives in Psychiatric Care. 2018;55(1):95-102. https://doi.org/10.1111/ppc.12307

6. Lee D, Heo SH, Yoon SS, Chang DI, Lee S, Rhee HY, et al. Sleep disturbances and predictive factors in caregivers of patients with mild cognitive impairment and dementia. Journal of Clinical Neurology. 2014;10(4):304-13. https://doi.org/10.3988/jcn.2014.10.4.304

7. Katz S, Stroud III MW. Functional assessment in geriatrics: a review of progress and directions. Journal of the American Geriatrics Society. 1989;37(3):267-72. https://doi.org/10.1111/j.1532-5415.1989.tb06820.x

8. Won CW, Rho YG, Kim SY, Cho BR, Lee YS. The validity and reliability of Korean activities of daily living (K-ADL) scale. Journal of the Korean Geriatrics Society. 2002;6(2):98.

9. Lawton MD, Brody E. Assessment of older people: self-maintaining and instrumental activities of daily living. The Gerontologist. 1969;9:179-86. https://doi.org/10.1093/geront/9.3_part_1.179

10. Lee MH, Yoon EK. A cross-validation of the Korean version of the revised memory and behavioral problems checklist (KRMBPC): exploratory and confirmatory analyses. Korean Journal of Social Welfare. 2007;59(2):65-88. https://doi.org/10.20970/kasw.2007.59.2.003

11. Zarit SH, Zarit JM. Cognitive impairment. In: Lewinsohn PM, Teri L, editors. Clinical geropsychology. Elmsford (NY): Pergamon Press; 1983. p. 38-81.
12. Teri L, Truax P, Logsdon R, Uomoto J, Zarit S, Vitaliano PP. Assessment of behavioral problems in dementia: the revised memory and behavior problems checklist. Psychology and Aging. 1992;7(4):622-31.

https://doi.org/10.1037/0882-7974.7.4.622

13. Alexopoulos GS, Abrams RC, Young RC, Shamoian CA. Cornell scale for depression in dementia. Biological Psychiatry. 1988; 3(3):271-84.

14. Lee Y, Lee YS, Hong GRS. Validation of Korean version of the Cornell scale for depression in dementia among older adults in long-term care facilities. Journal of Korean Gerontological Nursing. 2015;17(3):42-151.

https://doi.org/10.17079/jkgn.2015.17.3.142

15. Johns MW. A new method for measuring daytime sleepiness: the Epworth sleepiness scale. Sleep. 1991;14(6):540-5.

https://doi.org/10.1093/sleep/14.6.540

16. Mapi Research Trust. Epworth Sleepiness Scale (ESS) [Internet]. Lyon: Mapi Research Trust; 2015 [updated 2015; cited 2019 Apr 25]. Available from:

https://eprovide.mapi-trust.org/instruments/epworth-slee piness-scale

17. Radolff LS. The CES-D scale: a self-report depression scale for research for research in the general population. Applied Psychological Measurement. 1977;1(3):385-401.

https://doi.org/10.1177/014662167700100306

18. Chon KK, Rhee MK. Preliminary development of Korean version of CES-D. The Korean Psychological Association. 1992; 11(1):65-76.

19. Zarit SH, Reever KE, Bach-Peterson J. Relatives of the impaired elderly: correlates of feelings of burden. The Gerontologist. 1980;20(6):649-55. https://doi.org/10.1093/geront/20.6.649

20. Kwon JD. Measuring the caregiver burden of caring for the demented elderly. Yonsei Social Welfare Review. 1996;3(1): $140-68$.

21. Buysse DJ, Reynolds III CF, Monk TH, Berman SR, Kupfer DJ. The Pittsburgh sleep quality index: a new instrument for psychiatric practice and research. Psychiatry Research. 1989;28(2): 193-213. https://doi.org/10.1016/0165-1781(89)90047-4

22. Sohn SI, Kim DH, Lee MY, Cho YW. The reliability and validity of the Korean version of the Pittsburgh Sleep Quality Index. Sleep and Breathing. 2012;16(3):803-12. https://doi.org/10.1007/s11325-011-0579-9

23. Sharma N, Mishra R, Mishra D. The fifth edition of diagnostic and statistical manual of mental disorders (DSM-5): what is new for the pediatrician. Indian Pediatrics. 2015;52(2):141-3. https:// doi.org/10.1007/s13312-015-0589-y

24. Ohayon MM, Roth T. What are the contributing factors for insomnia in the general population? Journal of Psychosomatic Research. 2001;51(6):745-55. https://doi.org/10.1016/S0022-3999(01)00285-9 
25. Epstein-Lubow G. Family caregiver health: what to do when a spouse or child needs help. Geriatrics for the Practicing Physician. 2009;92(3):106-7.

26. Waelde LC, Meyer H, Thompson JM, Thompson L, GallagherThompson D. Randomized controlled trial of inner resources meditation for family dementia caregivers. Journal of Clinical Psychology. 2017;73(12):1629-41.

https://doi.org/10.1002/jclp.22470

27. Abrahams R, Liu KP, Bissett M, Fahey P, Cheung KS, Bye R, et al. Effectiveness of interventions for co-residing family caregivers of people with dementia: systematic review and metaanalysis. Australian Occupational Therapy Journal. 2018;65(3): 208-24. https://doi.org/10.1111/1440-1630.12464

28. Von Känel R, Mausbach BT, Ancoli-Israel S, Dimsdale JE,
Mills PJ, Patterson TL, et al. Sleep in spousal Alzheimer caregivers: a longitudinal study with a focus on the effects of major patient transitions on sleep. Sleep. 2012;35(2):247-55. https://doi.org/10.5665/sleep.1632

29. Arber S, Bote M, Meadows R. Gender and socioeconomic patterning of self-reported sleep problems in Britain. Social Science \& Medicine. 2009;68(2):281-9. https://doi.org/10.1016/j.socscimed.2008.10.016

30. Lee T W, Yim E, Cho E, Chung J. Cognitive function, behavioral problems, and physical function in long-term care insurance beneficiaries with dementia in South Korea: comparison of home care and institutional care services. Journal of the American Geriatrics Society. 2014;62(8):1467-75.

https://doi.org/10.1111/jgs.12944 